\title{
Free radical scavenging effects of the Philippine endemic medicinal plant Alpinia elegans (Zingiberaceae)
}

\author{
M.A.K. Naive ${ }^{1}$, J.A.G.P. Dalisay ${ }^{2}$, E.P.T. Maglangit ${ }^{1}$, \\ G.C. Cafe $^{1} \&$ O.M. Nuňeza ${ }^{1}$ \\ ${ }^{1}$ Department of Biological Sciences, College of Science and Mathematics, \\ Mindanao State University-Iligan Institute of Technology, Andres Bonifacio Ave, \\ Iligan City, 9200 Lanao del Norte, Philippines \\ arciinaive19@gmail.com \\ ${ }^{2}$ College of Teacher Education, Biological Science Department, \\ University of Antique, Tario-Lim Memorial Campus, 5707 Antique, Philippines
}

\begin{abstract}
Alpinia elegans (C.Presl) K.Schum. is an endemic Philippine medicinal plant used in the treatment of various conditions such as muscoloskeletal diseases, hemoptysis, headache, migraine, stomach ache, and as an anti-relapse for women. The major phytochemical constituents of the ethanolic extract from the leaves of Alpinia elegans were screened and their antioxidant activity was evaluated using an in vitro 1,1-Diphenyl-2-picrylhydrazyl (DPPH) free radical-scavenging (antioxidant) activity assay. Flavonoids, steroids, saponins, tannins, alkaloids, and cyanogenic glycosides were found to be present in the ethanolic leaf extract of Alpinia elegans, while anthraquinone was not detected. High DPPH radical scavenging (antioxidant) activity was observed in the ethanolic leaf extract of Alpinia elegans with a percentage DPPH inhibition of $95.11 \pm 1.00$ at $500 \mu \mathrm{g} / \mathrm{ml}$. The present study suggests that the leaf extract is a source of medicinal or pharmaceutical antioxidants. Information derived herein provides a preliminary scientific basis for the existing ethnobotanical knowledge of local communities.
\end{abstract}

Keywords. Ethanolic extract, DPPH radical scavenging activity, musculoskeletal diseases, phytochemistry

\section{Introduction}

Traditional medicine all over the world has recently gained more attention through research studies on different plant species and their therapeutic properties. The phytochemicals of the plants contain various bioactive compounds, including antioxidants, anti-inflammatories, and anticancer molecules. At present, about $25 \%$ of the active compounds have been identified from medicinal plants (Gill et al., 2011).

Free radicals play an important role in affecting human health by causing several chronic diseases, such as cancer, diabetes, atherosclerosis, hypertension, heart attacks and other degenerative diseases, as well as having a role in aging (Raghuveer $\&$ Tandon, 2009). Natural antioxidants of plant origin protect against these radicals and are, therefore, important tools in restoring and preserving good health (Brieger et al., 2012). Thus, natural compounds derived from plant tissues have received attention as novel antioxidants suitable for use in food and medicine. 
Zingiberaceae, or the gingers, are being explored worldwide for their high medicinal value and versatile nature. It is the largest family in the order Zingiberales with 56 genera and over 1,500 species, which are widely distributed throughout the tropics and are especially rich in Southeast Asia (De Boer et al., 2018). Many plants belonging to the family are used for food, spices, condiments, and traditional medicine (Kuo et al., 2008). The Philippines has about 108 species in 16 genera, although these figures only include the named species (Pelser et al., 2011 onwards). However the traditional uses of species of Zingiberaceae and their pharmacological properties, along with other ethnomedicinal plants, have received little attention in the Philippines (e.g. Mandap et al., 2007; Villaflores et al., 2010; Galang et al., 2016; So et al., 2016). Furthermore, given the increasing pace of forest destruction and loss of traditional knowledge, it is likely that some unknown or poorly known ginger species face extinction before their medicinal or other uses can be fully explored (Naive, 2017).

Alpinia elegans (C.Presl) K.Schum. (Fig. 1) is a species endemic to the Philippines, distributed in the provinces of Apayao, Ilocos Sur, Mountain Province, Isabela, Nueva Vizcaya, Pampanga, Bulacan, Nueva Ecija, Bataan, Rizal, Laguna, Quezon, Sorsogon, Polillo, Mindoro, Leyte and Antique, where it grows in various habitats (Pelser et al., 2011 onwards; Zingiberaceae Resource Centre, 2019). This species is locally known as "bayumbong pula" in the province of Antique and is listed as Vulnerable (DENR Administrative Order, 2017). It is a tall herb growing in forests. The rhizomes are fibrous in nature and some are cultivated as ornamental plants. The fruit is edible and the seed oil has a characteristic aroma. The plant is used in the treatment of musculoskeletal diseases (Blasco et al., 2014); juice from macerated young stems are used to treat urticaria; pounded leaves are mixed with a little salt and rubbed onto paralyzed extremities; and a decoction of rhizomes is used for hemoptysis (Stuart, 2018). Traditionally, the local people in Antique uses Alpinia elegans in the treatment of headaches, migraines, stomach ache and as an anti-relapse for women (Dalisay et al., 2018). Despite its reported ethnomedicinal uses, a phytochemical screening and the antioxidant activity of the ethanolic extracts of the leaves of Alpinia elegans have not hitherto been published.

\section{Materials and methods}

The leaves of Alpinia elegans were collected from the forest patches of La Paz, Tibiao, Province of Antique, Philippines. The plants were identified and confirmed by the first author (MAKN). Voucher specimens and spirit collections of the flowers were prepared and deposited in the University of Santo Tomas Herbarium (USTH).

The plant leaf samples were air-dried for three to four weeks, powdered using a blender, and stored inside an airtight plastic container prior to their extraction. Powdered leaf samples were soaked in absolute ethanol for 10 days and filtered. The solvent in the filtrate was removed in vacuo using a rotary evaporator at a temperature below $40^{\circ} \mathrm{C}$. The ethanol extract was stored inside a refrigerator prior to its usage. 

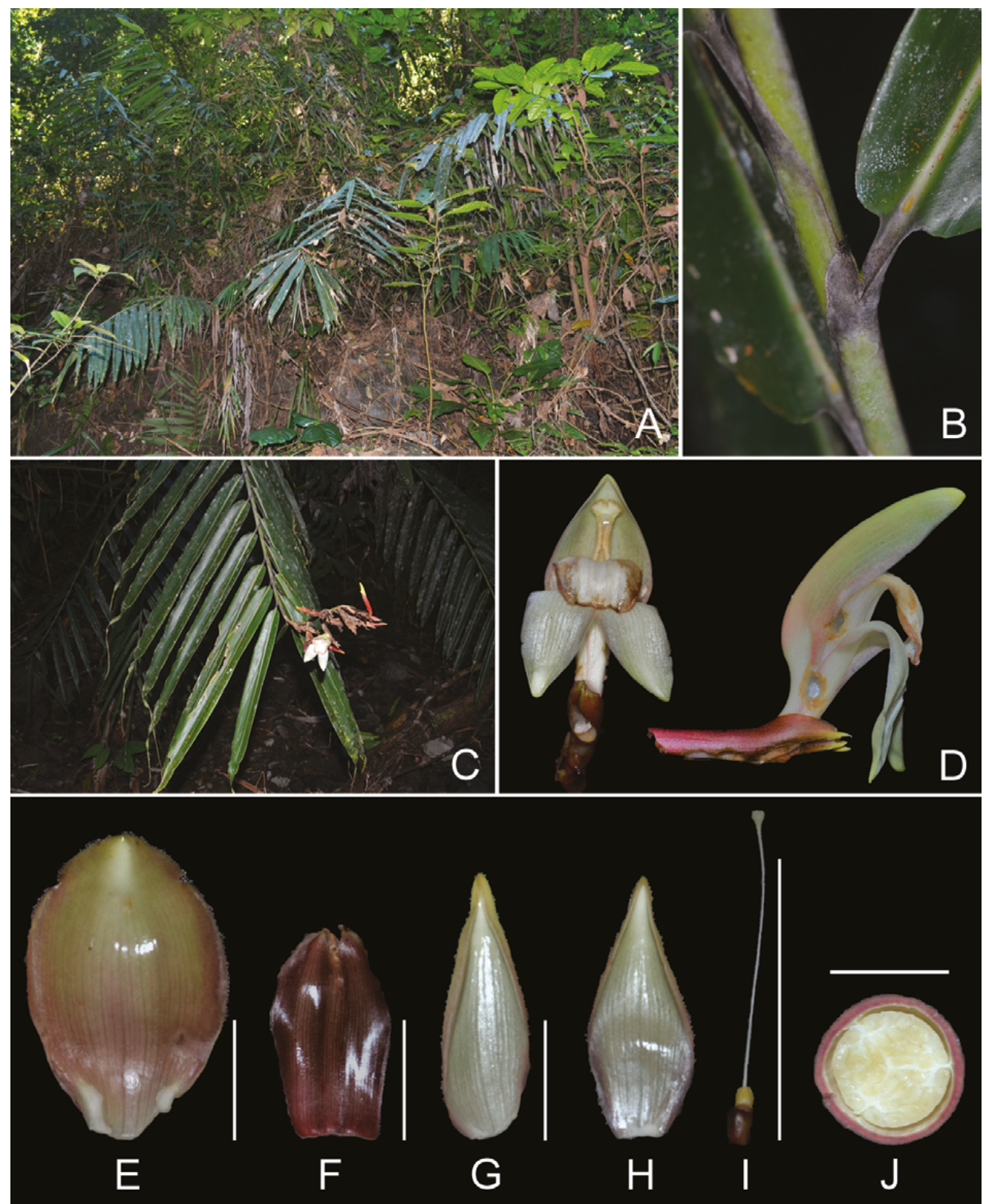

Fig. 1. Alpinia elegans (C.Presl) K.Schum. A. Habit. B. Detail of ligule. C. Leafy shoot with inflorescence. D. Flowers (Front view \& Lateral view). E. Bract, scale bar: $2 \mathrm{~cm}$. F. Calyx, scale bar: $2 \mathrm{~cm}$. G. Lateral corolla lobes, scale bar: $2 \mathrm{~cm}$. H. Dorsal corolla lobe. I. Ovary, epigynous glans, style, stigma, scale bar: $5 \mathrm{~cm}$. J. Transverse section of fruit, scale bar: $1 \mathrm{~cm}$. (Photos: All by J.A.G. Dalisay \& M.A.K. Naive). 
Ethanol extracts of Alpinia elegans were subjected to qualitative phytochemical screening for the determination of various classes of active chemical constituents using the method described by Guevarra et al. (2005).

DPPH radical scavenging activities of the ethanol extracts were determined using the method of Lee \& Shibamoto (2000). Briefly, various amounts of the samples $(500 \mu \mathrm{g} / \mathrm{ml}, 300 \mu \mathrm{g} / \mathrm{ml}, 200 \mu \mathrm{g} / \mathrm{ml}, 100 \mu \mathrm{g} / \mathrm{ml}, 50 \mu \mathrm{g} / \mathrm{ml}, 30 \mu \mathrm{g} / \mathrm{ml}, 20 \mu \mathrm{g} / \mathrm{ml}, 10 \mu \mathrm{g} /$ $\mathrm{ml})$ were mixed with $3 \mathrm{~mL}$ of ethanolic solution of DPPH $(0.1 \mathrm{mM})$. The mixture was shaken vigorously in a vortex mixer for 10 seconds and allowed to stand in the dark at room temperature for one hour. Then absorbance was measured at $517 \mathrm{~nm}$ against ethanol as a blank in the Lasany double beam UV-Vis spectrophotometer model LI2800 (Haryana, India). The DPPH solution alone in ethanol was used as a control. Each sample was assayed in triplicate and mean values were calculated. L-ascorbic acid was used as a standard. The radical scavenging activity of samples corresponds to the intensity of quenching DPPH. The percent DPPH discoloration of the samples was calculated and the results were expressed as percentage inhibition using the formula (equation 1) shown below:

$$
\% \text { Inhibition }=\left[\left(\mathrm{A}_{\text {control }}-\mathrm{A}_{\text {sample }}\right) / \mathrm{A}_{\text {control }}\right] \times 100
$$

where $\mathrm{A}_{\text {control }}$ and $\mathrm{A}_{\text {sample }}$ are the absorbance values of the control and test sample, respectively.

\section{Results}

It is well known that the antioxidant activity of plant extracts containing polyphenol components is due to their capacity to be donors of hydrogen atoms or electrons and to capture free radicals. The DPPH assay is one of the most widely used methods for screening antioxidant activity of plant extracts. In the present study, ethanolic extracts of the leaves of Alpinia elegans showed a signficant effect in inhibiting DPPH, reaching up to $95.11 \%$ at a concentration of $500 \mu \mathrm{g} / \mathrm{ml}$. Table 1 shows the percentage inhibition of the DPPH radical by the scavenging activity of the Alpinia elegans ethanolic extracts compared with the standard ascorbic acid. This is visually indicated by the discoloration of the DPPH solution from purple to yellow. The $\mathrm{IC}_{50}$ value of Alpinia elegans leaf extract was $97.58 \mu \mathrm{g} / \mathrm{ml}$ while the $\mathrm{IC}_{50}$ value of L-ascorbic acid was $1.80 \mu \mathrm{g} / \mathrm{ml}$. These values are lower compared to the standard L-ascorbic acid.

Phytochemical screening for secondary metabolites in ethanol extracts of leaves of Alpinia elegans revealed the presence of flavonoids, steroids, saponins, tannins, alkaloids and cyanogenic glycosides except anthraquinone as shown in Table 2. These phytochemical compounds are known to support bioactivities in medicinal plants and thus may be responsible for the antioxidant activities of the plant extract used in this study. 
Table 1. DPPH radical scavenging activity of the ethanol extracts of the leaves of Alpinia elegans and Ascorbic acid. - mean of 3 replicates and expressed as mean $\pm \mathrm{RSD}$

\begin{tabular}{|c|c|c|c|}
\hline \multicolumn{2}{|c|}{ A. elegans } & \multicolumn{2}{|c|}{ Ascorbic acid } \\
\hline $\begin{array}{c}\text { Concentration } \\
(\mu \mathrm{g} / \mathrm{ml})\end{array}$ & $\%$ Inhibition & $\begin{array}{c}\text { Concentration } \\
(\mu \mathrm{g} / \mathrm{ml})\end{array}$ & $\%$ Inhibition \\
\hline 10 & $13.89 \pm 0.00$ & 2 & $60.07 \pm 0.00$ \\
\hline 20 & $24.21 \pm 2.86$ & 3 & $83.91 \pm 0.20$ \\
\hline 30 & $25.93 \pm 2.39$ & 4 & $87.73 \pm 0.40$ \\
\hline 50 & $35.19 \pm 1.15$ & 5 & $91.55 \pm 1.00$ \\
\hline 100 & $54.23 \pm 4.05$ & 10 & $94.56 \pm 0.20$ \\
\hline 200 & $84.39 \pm 1.65$ & 20 & $94.44 \pm 0.00$ \\
\hline 300 & $91.80 \pm 1.28$ & $\mathrm{IC}_{50}$ & $1.80 \pm 0.06$ \\
\hline 500 & $95.11 \pm 1.00$ & & \\
\hline $\mathrm{IC}_{50}$ & $97.58 \pm 4.15$ & & \\
\hline
\end{tabular}

Table 2. Phytochemical profile of the ethanolic extracts of the leaves of Alpinia elegans. Legend: "+” Present, “-“ Absent, "+" poor, "++" moderate, "+++" heavy

\section{Phytoconstituents}

Flavonoids

Steroids

Saponins

Tannins

Alkaloids

Cyanogenic glycosides

Anthraquinone

\section{Interference}

$$
\begin{gathered}
+++ \\
+++ \\
+ \\
+++ \\
+ \\
+
\end{gathered}
$$




\section{Discussion}

\section{Antioxidant activity}

Renewed interest in plant antioxidants has emerged in recent years. Among plants used as traditional medicines, there are many different types of bioactive compound with antioxidant activity that play significant roles in terminating the generation of free radical chain reactions (Basma et al., 2011). Hence, in this study, we evaluated the antioxidant properties of Alpinia elegans through an in vitro antioxidant test.

Plants have long been an important source of drugs and many plants have been screened to see if they contain compounds with therapeutic qualities. DPPH is a stable, nitrogen-centred free radical, which produces a deep purple colour in ethanolic solution. The principle of this assay is based on the reduction of purplecoloured ethanolic DPPH solution in the presence of a hydrogen atom donating antioxidants by the formation of yellow-coloured diphenyl-picryl hydrazine. As the absorbance decreases, the more efficient the antioxidant activity of the extract in terms of hydrogen atom donating capacity. The more antioxidants present in the extract, the more DPPH reduction will occur. Our results suggest that the different concentrations have different activities and the maximum activity was observed at $500-\mu \mathrm{g} / \mathrm{ml}$ concentration. The observed antioxidant activity of extracts may be due to the neutralisation of free radicals (DPPH), either through the transfer of a hydrogen atom or by the transfer of an electron (Knezevic et al., 2011). The antioxidant activities shown in this study may be attributed to the presence of flavonoids in the ethanol extracts of leaves of Alpinia elegans. Several studies have shown an association of flavonoids to the antioxidant activity of plant extracts (e.g. Kumar et al., 2013; Sahoo et al., 2013). Zingiber officinale Roscoe and Alpinia nigra (Gaertn.) B.L.Burtt have been extensively reported as possessing antioxidant activity against a variety of free radicals (Kumar et al., 2011; Sahoo et al., 2013).

The antioxidant activity of the ethanol extract of leaves of Alpinia elegans was found to be twenty times lower than L-standard ascorbic acid. The results are similar to previous studies of four medicinal plants in the Philippines, namely Brucea javanica (L.) Merr. bark, Intsia bijuga (Colebr.) Kuntze, Laportea meyeniana (Walp.) Warb. and Pipturus arborescens (Link) C.B.Rob. leaves (Peteros \& Uy, 2010). Ethanol extracts of the endemic Zingiberaceae species Amomum muricarpum Elmer, Etlingera philippinensis (Ridl.) R.M.Sm. and Hornstedtia conoidea Ridl. in the Philippines showed a similar low level of antioxidant activity compared to L-ascorbic acid (Barbosa et al., 2016). The generally low activity of the plant extracts when compared to the L-ascorbic acid standard is to be expected (Peteros \& Uy, 2010).

\section{Phytochemical analysis}

Plants are important sources of potential compounds for the development of new therapeutic agents (Banerjee \& Bonde, 2011). In addition, natural products are gaining attention because of their perceived lower risk and potential utilisation in the nutraceutical and drug industries (Butt \& Sultan, 2011; Bua-in \& Paisooksantivatana, 2009). 
Alkaloids, flavonoids, saponins, tannins, and steroids found in the ethanol extracts of leaves of Alpinia elegans have also been observed in other Zingiberaceae species. Amomum muricarpum, Etlingera philippinensis and Hornstedtia conoidea were reported to contain alkaloids, flavonoids, saponins, tannins and steroids (Barbosa et al., 2016). The presence of these phytochemicals may explain the medicinal and therapeutic properties of the plant.

Flavonoids are the most widespread group of polyphenols. Flavonoids have been shown to exhibit their actions through effects on membrane permeability, and by inhibition of membrane-bound enzymes such as ATPase and phospholipase A2 (Li et al., 2003). Flavonoids have been reported to possess antiulcer, anti-inflammatory, antioxidant, cytotoxic, anti-tumor, antispasmodic and antimicrobial properties (Pacaňa \& Galarpe, 2017).

Plant steroids have cardiotonic activities and they are reported to be useful in the management of hypertension. Due to their structural similarities to various anabolic hormones, including sex hormones, plant steroids may have the potential to function as effective, natural, and safe alternatives to treat age- and disease-associated muscle loss, or to improve endurance and physical performance (Okwu, 2001). In addition, steroids are reported to have anti-bacterial, anti-tumor, hepatoprotective, anti-inflammatory, antigoitrogenic, and antidiarrhoeic properties (Patel \& Savjani, 2015).

Alkaloids have been reported to have broad-spectrum antibacterial properties and are also used as analgesics, narcotics for pain relief, and antispasmodics (Pacaňa \& Galarpe, 2017). However, as reported by Aniszewski (2007), selective biotoxicity is also a secondary function of these compounds.

Saponins are natural detergents found in many plants. They have several other pharmacological properties: anti-inflammatory, expectorant, immune stimulating, antineoplastic effects, anticoagulant, neuroprotective, anti-bacterial and antioxidant activity (Rao \& Gurfinkel, 2000; Shi et al., 2004; Mujeeb et al., 2014).

Cyanogenic glycosides were detected during the phytochemical analysis of ethanol extracts of leaves of Alpinia elegans at a very low concentration. They are natural toxins that are present in several food plants. Cyanide is formed following the hydrolysis of cyanogenic glycosides that occurs when the plant material is crushed, either during consumption or during processing of the food crop. Consumption of improperly processed cyanogenic plants can lead to chronic and acute health problems (Bolarinwa et al., 2016). The presence of cyanogenic glycosides does not immediately mean that the extract from the plant is toxic. Further study is necessary to ascertain the clinical safety of extracts and to determine appropriate concentrations for therapy.

\section{Conclusion}

The results of this study indicate that ethanol extracts of the leaves of Alpinia elegans possess antioxidants as shown by the DPPH radical scavenging activity. The results show that the leaves of Alpinia elegans contain phytochemical constituents which may be responsible for reported pharmacological activity. We, therefore, recommend that the 
species be tested for efficacy in wound healing, as an anti-inflammatory, antimicrobial, and anti-cancer agent. The principal phytochemicals present in the ethanol extract of the leaves of Alpinia elegans should also be quantified. Furthermore, the information derived could provide a preliminary scientific basis for the existing ethnobotanical knowledge of local communities across the Philippines.

ACKNOWLEDGEMENTS. We thank the Department of Science and Technology Accelerated Science and Technology Human Resource Development Program (DOSTASTHRDP) for the scholarship grant of the first, third and fourth authors; Dr Cesar G. Demayo and Enjelyn C. Gomez of the Department of Biological Sciences \& Chemistry in MSU-IIT for the technical assistance; Dr Allan Patrick Macabeo of the Department of Chemistry in UST for the constructive comments; and the anonymous reviewers.

\section{References}

Aniswezki, T. (2007). Alkaloids - secrets of life: Alkaloid Chemistry, Biological Significance, Applications and Ecological Role, 1st ed. Amsterdam: Elsevier.

Banerjee, S.K. \& Bonde, C.G. (2011). Total phenolic content and antioxidant activity of extracts of Bridelia retusa Spreng Bark: Impact of dielectric constant and geographical location. J. Med. Pl. Res. 5: 817-822.

Barbosa, G.B., Peteros, N.P. \& Inutan, E.D. (2016). Antioxidant activities and phytochemical screening of Amomum muricarpum, Hornstedtia conoidea and Etlingera philippinensis. Bull. Environ. Pharmacol. Life Sci. 5: 22-32.

Basma, A.A., Zakaria, Z., Latha, L.C. \& Sasidharan, S. (2011). Antioxidant activity and phytochemical screening of the methanol extracts of Euphorbia hirts L. Asian Pacific J. Trop. Med. 4: 386-390.

Blasco, F., De Guzman, G. \& Alejandro, G.J. (2014). A survey of ethnomedicinal plants in Surigao Del Sur Mountain Range, Philippines. Int. J. Pure Appl. Biosci. 2: 166-172.

Bolarinwa, O.A., Ameen, H.A., Sanya, E.O., Kolo, P.M., Durowade, K.A., Uthman, M.M.B., Ogunmodede, J.A., Biliaminu, S.A., Odeigah, L.O. \& Akande, T.M. (2016). Pattern and predictive factors of health-related quality of life of patients with hypertension, diabetes and concomitant hypertension with diabetes in Ilorin, Nigeria. Nigerian Postgrad. Med. J. 23: $182-90$.

Brieger, K., Schiavone, S., Miller, F.J. Jr. \& Krause, K.H. (2012). Reactive oxygen species: from health to disease. Swiss Med. Weekly 142: w13659.

Bua-In, S. \& Paisooksantivatana, Y. (2009). Essential oil and antioxidant activity of Cassumunar Ginger (Zingiberaceae: Zingiber montanum (Koenig) Link ex Dietr.) collected from various parts of Thailand. Kasetsart J. (Nat. Sci.) 43: 467-475.

Butt, M.S. \& Sultan, M.T. (2011). Coffee and its Consumption: Benefits and Risks. Crit. Rev. Food Sci. Nutr. 51: 363-373.

Dalisay, J.A.G., Bangcaya, P.S., \& Naive, M.A.K. (2018). Taxonomic studies and ethnomedicinal uses of Zingiberaceae in the mountain ranges of northern Antique, Philippines. Biol. Forum 10: 68-73. 
De Boer, H., Newman, M., Poulsen, A.D., Droop, A.J., Fér, T., Hiên, L.T.T., Hlavatá, K., Lamxay, V., Richardson, J.E., Steffen, K. \& Leong-Škorničková, J. (2018). Convergent morphology in Alpinieae (Zingiberaceae): Recircumscribing Amomum as a monophyletic genus. Taxon 67: 6-36.

DENR Administrative Order (2017). Updated national list of threatened Philippine plants and their categories. DAO 2017-11.

Galang, M.G., Macabeo, A.P., Chang, W.C., Isobe, M. \& Aguinaldo, A. (2016). Glucosides from the unripe fruit juice of Carica papaya Linn. (Caricaceae) cultivar 'Red Lady' with antioxidant activity. J. Funct. Foods 22: 358-362.

Guevarra, B.Q. (2005). A guidebook to plant screening: phytochemical and biological. Manila: UST Publishing House.

Gill, N.S., Bajwa, J., Sharma, P., Dhiman, K., \& Sood, S. (2011). Evaluation of antioxidant and antiulcer activity of traditionally consumed Cucumis melo seeds. J. Pharmacol. Toxicol. 6: 82-89.

Knezevic, S.V., Blazekovic, B., Stefan, M.B., Alegro, A., Koszegi, T. \& Petrik, J. (2011). Antioxidant activities and polyphenolic contents of three selected Micromeria species from Croatia. Molecules 16: 1454-1470.

Kumar, K.M., Asish, G.R., Sabu, M. \& Balachandran, I. (2013). Significance of gingers (Zingiberaceae) in Indian System of Medicine - Ayurveda: An overview. Ancient Sci. Life. 32: 253-261.

Kumar, G., Karthik, L. \& Rao, B. (2011). A Review on Pharmacological and Phytochemical Properties of Zingiber officinale Roscoe (Zingiberaceae). J. Pharm. Res. 4(9): 29632966.

Kuo, K.M., Lu, F.Y., Duh, M.H. \& Deng, S.L. (2008). A new species, Alpinia nantoensis (Zingiberaceae) from Taiwan. Taiwan J. Forest Sci. 23: 93-97.

Lee, K.G. \& Shibamoto, T. (2000). Antioxidant properties of aroma compounds isolated from soybeans and mung beans. J. Agric. Food Chem. 48: 4290-4293.

Li, H., Wang, Z. \& Liu, Y. (2003). Review in the studies on tannins activity of cancer prevention and anticancer. Zhong-Yao-Cai. 26(6): 444-448.

Mandap, K., Marcelo, R., Macabeo, A.P., Yamauchi, T., Abe, F., Franzblau, S. \& Aguinaldo, A. (2007). Antitubercular phenyldecanoids from the Philippine ginger (Zingiber officinale). ACGC Chem. Res. Commun. 21: 20-22.

Mujeeb, F., Bajpai, P. \& Pathak, N. (2014). Phytochemical evaluation, antimicrobial activity and determination of bioactive components from leaves of Aegle marmelos. BioMed Res. Int. 2014: 1-11.

Naive, M.A.K. (2017). Zingiberaceae of Kalatungan Mountain Range, Bukidnon, Philippines. Biosci. Discov. 8: 311-319.

Okwu, D. (2001). Evaluation of the chemical composition of medicinal plants belonging to Euphorbiaceae. Pakistan Veterin. J. 14: 160-162.

Pacaňa, J.S. \& Galarpe, V.R.K.R. (2017). Antiobacterial property of Atuna racemosa Rafin, Chrysolobalanaceae shell and kernel extracts (aqueous, methanol, ethyl acetate, and decoction). Int. J. Biosci. 11: 443-448.

Patel, S.S. \& Savjani, J.K. (2015). Systematic review of plant steroids as potential antiinflammatory agents: Current status and future perspectives. J. Pharmacol. 4: 121-125.

Pelser, P.B., Barcelona, J.F. \& Nickrent, D.L. (eds) (2011 onwards). Co's Digital Flora of the Philippines. www.philippineplants.org. Accessed 10 Apr. 2018. 
Peteros, N.P. \& Uy, M.M. (2010). Antioxidant and cytotoxic activities and phytochemical screening of four Philippine medicinal plants. J. Med. Plant. Res. 4: 407-414.

Raghuveer, C. \& Tandon R.V. (2009). Consumption of functional food and our health concerns. Pakistan J. Physiol. 5(1): 76-83.

Rao, A.V. \& Gurfinkel, D.M. (2000). The bioactivity of saponins, triterpenoid and steroidal glycosides. Drug Metabolism Drug Interact. 17: 211-235.

Sahoo, S., Ghosh, G., Das, D. \& Nayak, S. (2013). Phytochemical investigation and in vitro antioxidant activity of an indigenous medicinal plant Alpinia nigra B.L.Burtt. Asian Pacific J. Trop. Biomed. 3: 871-876.

Shi, J., Arunasalam, K., Yeung, D., Kakuda, Y., Mittal, G. \& Jiang Y. (2004). Saponins from edible legumes: chemistry, processing, and health benefits. J. Med. Food 7: 67-78.

So, P.B.T., Rubio, P., Lirio, S., Macabeo, A.P., Huang, H.Y., Corpuz, M.J.T. \& Villaflores, O.B. (2016). In vitro angiotensin I converting enzyme inhibition by a peptide isolated from Chiropsalmus quadrigatus Haeckel (box jellyfish) venom hydrolysate. Toxicon 119: 77-83.

Stuart, G. Jr. (2018). Philippine Medicinal Plants. http://www.stuartxchange.org/Tagbak.html. Accessed 11 Apr. 2018.

Villaflores, O., Macabeo, A.P., Gehle, D., Krohn, K., Franzblau, S. \& Aguinaldo, A. (2010). Phytoconstituents from Alpinia purpurata and their in vitro inhibitory activity against Mycobacterium tuberculosis. Pharmacogn. Mag. 6: 339-344.

Zingiberaceae Resource Centre (2019). Royal Botanic Garden Edinburgh. http://padme.rbge. org.uk/ZRC/welcome. Accessed 25 Jul. 2019. 